Results Our clinical volunteer workforce of over 65 individuals are now trained, giving great feedback about its usefulness, practical nature and fun delivery.

This successful model and project approach has since been applied to stage two, non-clinical volunteers, with over 170 now beginning their training.

Given the strength of feedback, we have now embedded a two-stage training programme for all new volunteers.

Conclusion This training ensures our volunteers are safe and effective in their role, that we are meeting our duty of care to them and are creating ambassadors of all volunteers.

As a cross-departmental initiative, it has broken down siloworking, significantly reduced risk, embedded key competencies and provided crucial investment in our volunteers.

\section{P-257 RECRUITING GRADUATE TALENT IN THE HOSPICE SECTOR - A CASE STUDY}

Megan Veronesi, James Glover. Royal Trinity Hospice, London, SW4 ORN

\subsection{6/bmjspcare-2016-001245.277}

Background Recruiting and retaining qualified and competent staff is one of the biggest challenges facing many hospices. There is a relatively untapped pool of highly qualified graduates who want to work in the charity sector however hospices are not on the radar for many. They may assume hospices are NHS organisations; that all jobs are clinical; or that working in death and dying is depressing. As local charities, hospices do not have the resources to run their own graduate schemes to challenge these perceptions.

Aims

- To attract highly qualified and competent staff

- To meet an identified skills gap

- To see an immediate return on our investment.

Methods We assessed our skills gap and developed a role description. We approached Charityworks, the leading UK non-profit graduate programme, to source us a graduate who met the criteria. The programme offers a nationwide recruitment campaign, a rigorous selection process, and ongoing development for the graduate over their 12 month placement. In 2014 we became the first hospice to host a Charityworks graduate trainee.

Results We have now hosted two graduates, one in a project management role and another in a communications role. Both graduates:

- have first class honours degrees (in Civil Engineering and in Law) from leading universities

- came with relevant skills and experience, in project and data management and in media management respectively

- had a swift and positive impact. Our first graduate's environmental sustainability project became organisational policy. Within 6 months, our second graduate contributed significantly towards our communications objectives, increasing Facebook likes by 30\% and Instagram followers by $115 \%$.

Conclusions Charityworks gave us access to a higher level of talent than we could have attracted individually, at a fraction of the cost of running a comparable scheme ourselves. We would encourage all hospices to tap into the pool of talented graduates available to them through the Charityworks scheme.

\section{P-258 PARTNERSHIP SIGNPOST GUIDE TO OVERSEAS NURSE RECRUITMENT AND THE CHILDREN'S PALLIATIVE CARE SECTOR}

${ }^{1}$ Gillian Dickson, ${ }^{2}$ Lavinia Jarrett. ${ }^{1}$ Together for Short Lives, Bristol, UK; ${ }^{2}$ Demelza Hospice Care for Children; ${ }^{10}$ Together for Short Lives

\subsection{6/bmjspcare-2016-001245.278}

Introduction The nursing workforce shortage in the UK is having a significant impact on voluntary sector children's palliative care services and is leading to increased recruitment of nurses from overseas to fill this gap.

Aims A national lead organisation worked in partnership with a local voluntary children's palliative care provider to produce a signpost guide providing factual information and recording the actual experiences of this provider organisation when bringing overseas nurses to the UK. This guide would be available to other providers in the sector and valuable as a worked case example for other organisations - along with presenting the policy context.

Methods We recorded an interview with the director of people and resources at the children's hospice: exploring what preparation happened there for the nurses arriving, how it went once the nurses were here, and what the learning points were including any cost/time benefits.

We then added into the guide detailed factual information about immigration rules and policy - in the context of the current shortage of children's nurses in children's palliative care.

Results Providers in the children's palliative care sector can now see the detail of a worked example of one provider recruiting from overseas in this colourful guide - as well as ensure they are up to date with the detail of immigration legislation and how it may affect their workforce planning.

Conclusion Recruitment challenges are already having an effect on the care delivered by voluntary children's palliative care organisations - this has been measured over two consecutive years and shows the continued vacancy level is having an increasingly negative effect.

Some children's hospices will now be considering recruitment from beyond the UK - or will be continuing this practice where they already do it. This guide offers a resource on the rules of employing nurses from overseas and highlights the current situation in the global migration of nurses.

\section{P-259 ABSTRACT WITHDRAWN}

\section{P-260 WELLNESS FOR YOU: A STAFF WELLBEING RESOURCE FOR THOSE WHO WORK IN END OF LIFE CARE}

Kelly De Souza, Chris Haywood. Willowbrook Hospice, Prescot, UK

\subsection{6/bmjspcare-2016-001245.279}

Background Increasingly, compassion fatigue, staff welfare and 'burnout' of those working in end-of-life services is hitting the headlines. Whilst working in palliative care is rewarding it can often be challenging and impact on work life balance. Healthcare professionals in particular are considered to be at high-risk of compassion fatigue. The drive to support staff is increasingly important with high staff turnover, high sickness, poor morale and staff leaving the profession altogether. A Staff Wellbeing 
Strategy could negate these effects by improving overall wellbeing.

What are we doing As part of our strategy we have developed a free weekly programme of in house workshops called Wellness for You. Delivered by a senior complementary therapist the focus is on key elements of wellbeing; using different themes; informal interactive group discussions; practical demonstrations; attendees complete anonymised pre/post evaluations using a likert scale.

\begin{tabular}{ll}
\hline $\mathbf{W k}$ & Themes \\
\hline 1 & Wellness/wellbeing \\
2 & Resolutions, memories and moments \\
3 & Why little things matter \\
4 & Self-reliance \\
5 & Hand and arm massage \\
6 & Guided visualisation/meditation \\
7 & Not comparing be ourselves \\
8 & Developing a good sleep routine \\
9 & Happiness \\
10 & Grounding techniques \\
11 & 5 Senses and I \\
12 & Self-confidence \\
\hline
\end{tabular}

Objectives To develop a self- care resource for staff support; Improve health and energy; Improve satisfaction in the workplace; Reduce compassion fatigue

Results Early results from weekly evaluations have shown that the programme so far is proving to be a great success in creating an improved sense of wellbeing by reducing stress and improving morale - thus improving overall health in the long term.

Sustainability The workshops offer a rolling programme that can be used across all departments and in other settings. The programme has already shown benefits for staff in the work place even at this early stage. The focus is on supportive tools and strategies for self-care that all staff can benefit from. Developments of the programme may have human resource benefits i.e. reductions in staff turnover and absenteeism, higher morale and a better workplace to attract staff.

\section{\begin{tabular}{|l|l}
\hline P-261 DEVELOPING A RESILIENT WORKFORCE &
\end{tabular}}

Gill Thomas, Claire McCormack, Emma Knivett, Lisa Flanagan, Del Hughes, John Lansdell. Princess Alice Hospice, Esher, UK

\subsection{6/bmjspcare-2016-001245.280}

Background The last decade has seen considerable changes in end-of-life care, with patients living longer and more complex lives. Palliative care staff have to respond and adapt to these changes. Working in palliative care is associated with the stress of caring for people and organisational life (Hospice UK, 2015). Employers therefore have a role in supporting staff to develop techniques to help them cope (Hill et al., 2016).

Aims To develop supportive services to develop and maintain hospice staff resilience

Method A multidisciplinary wellbeing steering group designed a programme of workshops to identify what clinical and non-clinical staff found stressful about their everyday work life and designed interventions to support them. There were common themes across the whole workforce. Initiatives were developed alongside current supportive services (i.e. clinical supervision). These were:
- A booklet, 'Looking after yourself' supporting a resilient workforce given to all staff and all recruited staff

- A non-clinical staff support forum established

- A week designated as 'Resilience week' with range of workshops offered

- A relaxation CD devised by the therapy team, made available for staff as an MP3 file for free.

Findings 131 attended and 99 individual staff took part in 13 sessions. Of those attending 62\% were non-clinical and 38\% clinical. Eighty percent of those attending sessions said they would use strategies they learned from the sessions they attended.

Conclusions The engagement and interest during resilience week was extremely positive, we see this as the first of a series of initiatives. Embedding this initiative to safeguard to the mental health and wellbeing is essential and is the start of an ongoing initiative. Implications for practice To build on the positives outcomes from resilience week more initiatives are required. e.g.

- Mindfulness training

- Working with 'Mind' to provide mental health awareness training.

\section{P-262 FEASIBILITY OF OFFERING LOW DOSE MINDFULNESS TRAINING TO HEALTHCARE ASSISTANTS IN A HOSPICE IN-PATIENT UNIT SETTING}

${ }^{1}$ Susan Salt, ${ }^{2}$ Trish Bartley, ${ }^{3}$ Christina Shannon, ${ }^{1}$ Anita Griggs. ${ }^{1}$ Trinity Hospice, Blackpool, UK; ${ }^{2}$ School of Psychology Bangor University; ${ }^{3}$ Vine House Support Centre, Preston

\subsection{6/bmjspcare-2016-001245.281}

Building a resilient workforce with a care setting like a hospice, where there are constant demands on staff physically and emotionally is essential if compassion is to be retained and patient focussed care delivered. We decided to pilot a "low dose mindfulness" course to health care assistants, drawn from elements of more established eight-week course.

Nine health care assistants in a hospice have been recruited to attend three $\times 3$ and $1 / 2$ hour mindfulness training sessions over a four week period to see if it was feasible and acceptable to this group of staff who would not normally have access to such training.

Each session is conducted by a trained mindfulness teacher, supported by a second trainer and evaluated by the participants. Between the sessions the participants are encouraged to practice the techniques they had learnt at work and at home.

Full evaluation of the pilot will be presented at the conference. Each participant will have completed a self-compassion scale and an abbreviated Malscah burnout inventory pre and post training as well as participating in a semi structured interview with an independent research practitioner about their experience.

Initial response after the two training sessions that have been completed is that all the participants have enjoyed the sessions and found the training useful, but have struggled to put the training into practice at work, although have completed some of the practices in their own time at home.

It is hoped to run the course again once the pilot has been evaluated to a larger number of healthcare assistants involved in the care of patients approaching the last days of life to see if a "low dose of mindfulness training" can impact on the sense of well-being of staff. It is hoped that if the concept is proved that further research will be able to be conducted into its impact on the care delivered to patients. 